India, a body which he himself first suggested in his address as president of the Indian Science Congress Association meeting in Bombry in 1934.

\section{Urology and Medical Physics at Leeds}

THe Council of the University has accepted a gift of up to $£ 60,000$ from the Wellcome Trustees towards the cost of building research laboratories for medical physics and urology. The laboratories will be built on $a$ site at the General Infirmary at Leeds, and it is expected that substantial contributions will be made by the United Leeds Hospitals Board and the University to meet additional costs of the building and its equipment. The total cost is expected to be about $£ 120,000$.

The Department of Urology in the teaching hospital, the General Infirmary at Leeds, was established in October 1950. At the same time, a Department of Urology was established in St. James's Hospital, Leeds, the two hospital departments co-operating to form one urological unit for the city, Mr. L. N. Pyrah being appointed consultant surgoon to the unit. In October 1956 the University appointed Prof. Pyrah to a personal chair in urological surgery-the first chair of its kind in Great Britain. The Medical Research Council accepted major responsibility for the research programme of the Urological Unit and helped in creating a clinical research unit for the study of urological and surgical metabolism under the honorary directorship of Prof. Pyrah, with Dr. F. M. Parsons as assistant director. The University Department of Medical Physics has developed from the earlier Physics Department in the General Infirmary at Leeds. 'The University Department was founded in 1950, to further the application of physical methods to clinical research : in collaboration with many departments of the teaching hospital, its work includes investigation of problems bearing directly on the treatment of patients. When established by the University in 1950, the chair of medical physics, to which Prof. F. W. Spiers was appointed, was the first chair of its kind in Great Britain outside London. The clinical work and research programmes of the Urological Unit and the University Department of Medical Physics have developed in increasingly close association, and have both been assisted by the financial support of the Yorkshire Council of the British Empire Cancer Campaign and the Leeds Regional Hospital Board as well as the United Leeds Hospitals Board and the University.

The Urological Unit has developed work upon problems which have included biochemical studies following certain operations for cancer of the bladder and other conditions for which deviation of the urinary stream is necessary, clinical and biochemical studies in cases of renal failure due to advanced kidney disease and severe cases of prostatic obstruction, and also cases of stones in the kidney; in August of last year an artificial kidney was provided by the Board of Governors of the Teaching Hospital for the treatment of the most serious cases of renal failure. In medical physics, extensive work has been done on the application of radioisotopes to medical problems, frequently jointly with the Urological Unit on problems mentioned above. In addition, work is being done on the development of electronic methods as a means of providing better methods of measuring and recording the small electrical signals occurring in muscle and brain ; and, in another field, electronic scanning, as in a television camera, is being applied to intensify the X-ray screen image. The Department has developed a special interest in the measurement of body radioactivity, and the first international conference on this subject was held in Leeds in April 1956. With the sensitive apparatus now at the Department's disposal, it is possible to detect any small excess activity which may have been acquired occupationally or in other ways-an important safe. guard in the development and use of new radioactive materials. The Department has devoted much research also to the physical aspects of X-ray and radium therapy, and the results of its investigations on radiation absorption in bone have been widely applied in radiological work. Thus, these programmes of work in urology and medical physics together underline a development which is becoming increasingly a feature of modern medicine the growth of an extremely close partnership between the medical man in his concern with clinical research upon disease in the patient, and the scientist in his primary concern with fundamental physical, chemical and biochemical problems.

\section{Hungarian Refugee Students}

ThE Senate of the University of London has made available $£ 1,000$ for the immediate operation of 41 Tavistock Square as a reception centre for refugee Hungarian students. The house was cleaned and partly redecorated by students of the University and furniture has been obtained on loan from the London Hostels Association. Similar arrangements have been made in 12 Princes Gardens, which the Imperial College of Science and Technology has organized as an annexe to 41 Tavistock Square to accommodate sixteen students. The Senate on December 19 voted a further $£ 1,000$ to cover the needs of both centres for the immediate future. Fifty-five Hungarian refugee students are temporarily accommodated at 41 Tavistock Square, 12 Princes Gardens, Canterbury Hall, College Hall and Nutford House.

The universities of Britain have agreed to accept and maintain one hundred and fifty Hungarian refugee students. London's share is thirty-four. The Senate has approved a scheme for registration of refugee students from Hungary who provide satisfactory evidence of a qualification to matriculate in a university or institution of equivalent rank, and who have been prevented from pursuing courses of study or have suffered interruption in their courses through political circumstances.

\section{Synthetic Detergents}

THE Standing Technical Committee on Synthetic Detergents, the formation of which was announced in the House of Commons by the Minister of Housing and Local Government on December 18, has now been appointed, in consultation with the Secretary of State for Scotland, with the following membership : Chairman: H. W. Cremer, partner in the firm of Cremer and Brearley, consulting chemical engineors; Members : Dr. N. R. Beattie, principal medical officer, Ministry of Health; Dr. E. A. B. Birse, chief inspector of alkali works and rivers pollution in Scotland; Dr. A. H. Cook, assistant director, Brewing Industry Research Foundation; H. R. Galleymore, head of research and development, Thomas Hedley and Co., Ltd.; W. E. Hamer, general research manager, Monsanto Chemicals, Ltd.; Dr. G. C. Hampson, research manager, Unilever, Ltd., Port Sunlight; Dr. S. H. Jenkins, 